\title{
Is the Patient Activation Measure a valid measure of osteoarthritis self-management attitudes and capabilities? Results of a Rasch analysis
}

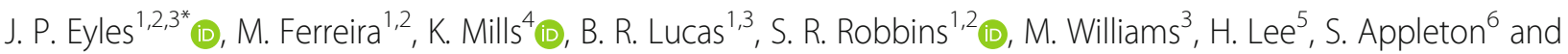

D. J. Hunter ${ }^{1,2}$

\begin{abstract}
Background: The Patient Activation Measure (PAM-13) was developed using Rasch analysis to assess knowledge, skills and confidence in the management of one's health. Previous studies report positive relationships between PAM-13 scores, self-management behaviours and longitudinal health outcomes in adults with chronic disease. There is little extant measurement property evidence for the use of PAM-13 in specific osteoarthritis (OA) populations. This study tested measurement properties of the PAM-13 in people living with hip and knee OA.
\end{abstract}

Methods: Item response frequency analysis was conducted. Rasch analysis evaluated the fit of the PAM-13 data to the Rasch model. Model-data fit was evaluated using infit and outfit statistics; person/item reliability and person separation indices were computed. Unidimensionality was evaluated using Principal Components Analysis of Rasch residuals and the data were assessed for item redundancy. Differential Item Functioning (DIF) examined bias in respondent subgroups and correlations tested relationships between PAM-13 and other patient-reported outcomes.

Results: Two-hundred-and-seventeen PAM-13 surveys were completed; there were no missing responses, floor or ceiling effects. Person and item reliability were acceptable ( 0.98 and 0.87 respectively) with good separation (person separation index 2.58). Unidimensionality was evaluated, with $49.4 \%$ of the variance explained by the first eigenvector. There was evidence of potential local response-dependence. The Rasch fit statistics were acceptable (except for item2). There were some issues identified with targeting of the PAM-13 items to people with higher ability and the item difficulty order was different to that proposed in original cohorts. Significant DIF was identified for sex and educational level for a small number of items. PAM-13 scores were moderately correlated with depressive symptoms on the Depression Anxiety Stress Scale and Assessment of Quality of Life-6D. There were small correlations between PAM-13 and Knee injury and Osteoarthritis Outcome Score pain and activities of daily living scores.

(Continued on next page)

\footnotetext{
*Correspondence: jillian.eyles@sydney.edu.au

'Kolling Institute of Medical Research, Institute of Bone and Joint Research,

Faculty of Medicine and Health, University of Sydney, Sydney, Australia

${ }^{2}$ Department of Rheumatology, Royal North Shore Hospital , Sydney,

Australia

Full list of author information is available at the end of the article
}

(c) The Author(s). 2020 Open Access This article is licensed under a Creative Commons Attribution 4.0 International License, which permits use, sharing, adaptation, distribution and reproduction in any medium or format, as long as you give appropriate credit to the original author(s) and the source, provide a link to the Creative Commons licence, and indicate if changes were made. The images or other third party material in this article are included in the article's Creative Commons licence, unless indicated otherwise in a credit line to the material. If material is not included in the article's Creative Commons licence and your intended use is not permitted by statutory regulation or exceeds the permitted use, you will need to obtain permission directly from the copyright holder. To view a copy of this licence, visit http://creativecommons.org/licenses/by/4.0/. The Creative Commons Public Domain Dedication waiver (http://creativecommons.org/publicdomain/zero/1.0/) applies to the data made available in this article, unless otherwise stated in a credit line to the data. 


\begin{abstract}
(Continued from previous page)
Conclusions: This study provides some evidence of adequate person and item reliability, unidimensionality, and construct validity to support the use of PAM-13 to measure patient activation in people living with hip and knee OA. Possible limitations regarding targeting, different item difficulty order, DIF and local response dependence should be investigated in future research.
\end{abstract}

Keywords: Measurement properties, Rasch, Osteoarthritis, Psychometrics, Patient activation

\section{Background}

Osteoarthritis $(\mathrm{OA})$ is a prevalent, painful condition and a leading cause of global disability [1]. As a costly [2], chronic, incurable disease, self-management interventions are recommended for the management of osteoarthritis (OA) [3]. Two systematic reviews have evaluated the effects of selfmanagement interventions that included OA patients. The first demonstrated evidence of small to moderate effects in terms of pain and functional improvements conferred by arthritis self-management interventions [4]. The second was concerned specifically with OA self-management education programs and found no or small benefits from these programs [5]. These reviews highlight that measures of pain and function are the most common primary outcomes for self-management interventions $[4,5]$. Whilst pain and function are obviously important to this population, there is a disparity between the aims of selfmanagement programs and the outcomes used to assess efficacy. A more meaningful measurement of program efficacy would be to measure OA self-management attitudes and capabilities [5], which have been recognised as comparatively neglected domains [6].

The measurement of OA self-management attitudes and capabilities requires validated instruments that have demonstrated adequate measurement properties in populations with OA [7]. Measurement properties refer to the ability of the instrument to accurately and comprehensively measure the specified construct [8] (e.g. internal consistency, reliability, validity). A recent systematic review of instruments assessing OA self-management attitudes and capabilities found that there was very little measurement property evidence available and that further research was needed to fill this knowledge gap [9].

An instrument identified in the review was the Patient Activation Measure (PAM-13); a patient-reported outcome assessing the knowledge, skill and confidence in the management of one's health [10]. The measurement properties of the PAM-13 have been studied in populations with varying chronic conditions including mental illness [11], neurological disorders [12] and multimorbidity [13, 14]. Two previous studies investigated measurement properties of the PAM-13 in OA populations. The first translated the PAM13 into Korean and provided some evidence of adequate internal consistency and structural validity [15]. The second examined the responsiveness of PAM- 13 in a sample of people with "arthritis", not specifically OA [16]. This study aims to provide further evidence of measurement properties of the PAM-13 in people living with OA.

Several large cohort studies report that higher levels of patient activation measured by the PAM-13 predict better selfmanagement behaviours and longitudinal health outcomes in adults with chronic disease [17-19]. This considered, it may be possible to predict patient outcomes following OA management programs using PAM-13 scores. This would enable the identification of people likely to experience a positive treatment effect. These people could then be prioritised for participation in these programs. Conversely, people reporting poorer self-management attitudes and capabilities may be identified and targeted for supplementary therapies (e.g. motivational coaching). Further, the efficacy of OA management programs could be measured in terms of change in patient activation. Before these potential uses of the PAM-13 are tested, it is important to establish that its measurement properties are acceptable in the OA population.

The PAM-13 developers used Rasch analysis to construct the instrument according to the Rasch measurement model [10]. The Rasch model determines the measurement requirements for the construction of interval level measurement scales [20]. A major advantage of using instruments developed using Rasch analysis is that the measurements can be assumed to produce interval level variables, hence, statistical tests requiring interval level variables can be used to report the results of clinical studies [21]. Rasch analysis also provides a unified measurement approach to test the validity of an instrument developed using this method when it is tested in a different population of patients [7]. This study had the following aims:

i) To test the measurement properties including reliability (internal consistency), unidimensionality (structural validity) and construct validity and floor/ceiling effects of the PAM-13 in people with hip and knee OA.

ii) To examine the relationships between PAM-13 scores and psychological, quality of life and diseasespecific outcomes.

\section{Methods}

\section{Participants}

This cohort study comprised participants of OA management programs (OAMP). Participants were recruited 
directly from Royal North Shore, Ryde (major teaching hospitals), Hunter's Hill Private and Mount Wilga (private metropolitan hospitals) hospitals in Australia via referral from rheumatologists, orthopaedic surgeons and general practitioners or joint arthroplasty waiting lists. People with symptomatic and radiographic hip and knee OA were eligible if they reported pain in the affected knee/hip on most days of the past month. Details of the program are published elsewhere [22]. Ethical approval for this study in accordance with the Declaration of Helsinki was provided by Human Research Ethics Committees: NSPHEC 2016-LNR-007; NSPHEC 2017-LNR-005 and LNRI16/HAWKE/14. Participants provided written consent to take part in this study prior to the start of the investigation.

\section{Data}

All data were collected at the baseline assessment of OAMP as part of the normal clinical pathway. Signal joint, the predominant site of OA, was determined by clinical and radiographic examination. Anthropometric measurements were undertaken using a standardised protocol [23]. Participants rated their average pain on the day of assessment using a Numeric Rating Scale $(0$ indicated no pain and 10 the most pain imaginable) [24]. Patient-reported outcomes were collected electronically as described below.

\section{Patient Activation Measure-13}

Participants rated their level of agreement with 13 statements (Table 1) using a 4-point Likert scale: Totally Disagree, Disagree, Agree, Totally Agree and Not Applicable (N/A). This outcome assumes that Item-1 is the easiest to endorse, and each subsequent item is more difficult to endorse than the one before [10]. The response (range 1-4) to the items are added to calculate a raw score. Responses of "not applicable" (N/A) are treated as missing. Scoring of the PAM-13 allows for any number of missing values, both items that are left blank and those with "not applicable" responses [25]. A continuous activation score is computed from the raw score using an empirically derived calibration table by Insignia Health (after January 2014). Total scores range from 0 (no activation) to 100 (high activation) [10]. PAM-13 score thresholds are used to assign four stages of activation in order of ascending activation: 1. "Believes active role is important"; 2. "Confidence and knowledge to take action"; 3. "Taking action"; 4. "Staying the course under stress" [10].

\section{The hip disability and osteoarthritis outcome score (HOOS) and knee injury and osteoarthritis outcome score (KOOS)} The HOOS [26] and KOOS [27] are disease-specific measures that have been validated in people with OA. Participants rate their symptoms, stiffness, pain, physical function, recreational activities and quality of life on a 5-point Likert scale $(0-4)$. The responses for the six subscales are summed and transformed to comprise six independent subscores; lower scores indicate worse problems.

\section{The depression, anxiety and stress scale (DASS-21)}

Participants rate their level of agreement with 21 statements using a 4-point Likert scale (0-3). The DASS-21 subscores indicate the presence/absence of symptoms of depression, anxiety and stress [28]. Higher scores indicate worse symptoms.

Table 1 Patient Activation Measure- 13 items and mean scores of responses

\begin{tabular}{|c|c|c|}
\hline PAM-13 items & $\mathrm{N}$ & $\operatorname{Mean}^{\mathrm{a}}(\mathrm{SD})$ \\
\hline 1. When all is said and done, I am the person who is responsible for taking care of my health & 217 & $3.4(0.73)$ \\
\hline 2. Taking an active role in my own health care is the most important thing that affects my health & 217 & $3.4(0.77)$ \\
\hline 3. I am confident I can help prevent or reduce problems associated with my health & 217 & $3.3(0.77)$ \\
\hline 4. I know what each of my prescribed medications do & 200 & $3.3(0.70)$ \\
\hline $\begin{array}{l}\text { 5. I am confident that I can tell whether I need to go to the doctor or whether I can take care of } \\
\text { a health problem myself }\end{array}$ & 215 & $3.2(0.70)$ \\
\hline 6. I am confident that I can tell a doctor concerns I have even when he or she does not ask & 217 & $3.3(0.65)$ \\
\hline 7. I am confident that I can follow through on medical treatments I may need to do at home & 216 & $3.2(0.67)$ \\
\hline 8. I understand my health problems and what causes them & 215 & $3.1(0.71)$ \\
\hline 9. I know what treatments are available for my health problems & 212 & $2.8(0.75)$ \\
\hline 10. I have been able to maintain (keep up with) lifestyle changes, like eating right or exercising & 210 & $2.8(0.70)$ \\
\hline 11. I know how to prevent problems with my health & 208 & $2.6(0.70)$ \\
\hline 12. I am confident I can figure out solutions when new problems arise with my health & 212 & $2.8(0.70)$ \\
\hline $\begin{array}{l}\text { 13. I am confident that I can maintain lifestyle changes, like eating right and exercising, even } \\
\text { during times of stress }\end{array}$ & 216 & $2.8(0.70)$ \\
\hline
\end{tabular}

aPAM items are scored using "Totally Disagree" $=1$, "Disagree" $=2$, "Agree" $=3$, "Totally Agree" $=4$ 


\section{Assessment of quality of life (AQoL-6D)}

Participants respond to questions or statements rated using four, five, or six point scales. Six dimensions are reported separately including independent living, relationships, mental health, coping, pain and senses which are combined for a standardised AQoL index. Higher scores indicate a worse quality of life [29].

\section{Statistical analysis}

Descriptive statistics and correlations were processed using SPSS (Version 22.0, Armonk NY: IBM Corp, USA) software. The PAM-13 responses were compared to the Rasch model with Rasch analysis [20] using Winsteps (version 4.0.1 Linacre, J. M. (2017) Winsteps ${ }^{\bullet}$ Rasch measurement computer program. Beaverton, Oregon: Winsteps.com).

\section{Item response frequency analysis}

Item response analysis was conducted to demonstrate data quality [30]. The frequencies of each response option and missing responses were reported for each item. Floor and ceiling effects were confirmed if $\geq 15 \%$ of respondents answered "totally disagree" or "totally agree" to all items respectively [31].

\section{Rasch model overview}

The PAM-13 was originally developed using Rasch analysis [10]. A Rasch analysis compares individual items or responses of a patient-reported outcome measure with a Rasch model (RM) [21]. Comparison to a Rasch Model provides insight into whether scores obtained for individual items of the outcome measure can be added together to create an overall score. More specifically, it assists in determining whether the outcome measure possesses the properties of an interval scale or whether each item is stand-alone.

The RM assumes that responses to the items of an outcome scale are affected by the ability of the person and the difficulty of the item [32]. In Rasch analysis, metrics are calculated to determine whether the relationships between the ability of the person and the difficulty of the item in the study data are consistent with what would be expected to fit the RM and that the assumptions of the RM are met. In outcome scales that use ordered response categories, such as Likert scales used in the PAM-13, the partial credit Rasch model (PCM) can be used. The PCM allows for differing levels of response, between complete agreement and complete disagreement, with each item on the scale. Therefore, each item can be partially agreed, or disagreed with by a respondent. 'Person ability' is calculated using the number of items of the instrument that a person agreed or partially agreed with. 'Item difficulty' is estimated using the number of persons in the sample who agreed or partially agreed with an item [32]. The relationship between person ability and item difficulty is clearly depicted on person-item maps. Measures of fit are used to assess whether the instrument conforms to RM requirements; infit and outfit statistics are used to indicate how accurately or predictably data fit the model [33]. There is not complete agreement about the influence of sample size on fit statistics, however, a sample of 200 participants has been recommended [34]. For this study, we aimed to recruit 250 to account for $20 \%$ noncompletion rate.

\section{Reliability and separation}

In Rasch analysis, the person reliability index estimates the probability that the ordering of persons (based on their abilities) is preserved when they respond to further items measuring the same construct. The Item reliability index indicates the probability that the order of the items (based on difficulty) would be the same if the same construct was measured in a similar but independent sample of people [32]. The person separation index tests if the instrument is sensitive enough to distinguish between people with high and low abilities. Thresholds for acceptable indices were set at $>0.8$ for item reliability, > 0.8 for person reliability and $>2$ for person separation index [31, 33]. The person-item map was used as a pictorial representation of how well the difficulty of the items aligned with the abilities of the persons who completed the survey. The alignment between item difficulty and person ability is referred to as 'targeting' [32].

\section{Rasch model fit analysis}

The partial credit model was used to examine modeldata fit; it was chosen because the PAM-13 items were measured on a four-point Likert scale with ordinal response options [32]. Point-measure correlations were estimated to determine whether item responses aligned with person abilities. Point measure correlations $>0.5$ were considered acceptable. Infit and outfit statistics (expressed in mean square $(\mathrm{MnSq})$ ) indicated how well the data fit the RM. Values between 0.5 and $1.5 \mathrm{MnSq}$ were considered acceptable [32]. An approximate global log-likelihood chi-squared statistic for overall goodness of fit was computed to indicate if the misfit of the data was large enough to be problematic [33].

\section{Instrument performance improvement}

Rasch analysis can be used to identify overlapping items measuring similar aspects of the construct and/or items that do not fit the model well; termed item redundancy. Fit statistics (MnSq values) indicated whether an item might be redundant and considered for removal from the model [32]. Overlapping items were also identified using the Rasch person-item map as those occupying the 
same location on the map. To confirm item redundancy as identified using fit statistics and/or the person-item map, it was also necessary to assess whether the content of the item overlapped with any aspect of another item. If two or more items were similar in content, this might indicate redundancy. Following item removal, fit statistics and person-item maps confirmed whether model fit was improved.

\section{Unidimensionality}

In Rasch analysis, structural validity is determined by confirming the unidimensionality of the construct [30]. Winsteps uses a Principal Components Analysis (PCA) to create potential secondary dimensions (termed contrasts) based on the unexplained variance of the residuals, measured in eigenvalue units. The Winsteps PCA of residuals is not interpreted in the same way as Factor Analysis (FA) of the original data in classical test theory (CTT). For this analysis, the threshold for good evidence of unidimensionality was provided by an eigenvalue of less than 2.0 on the first contrast; (larger eigenvalues indicated the need for further investigation) [33]. Where eigenvalues exceeded 2.0, a CTT factor analysis of the original data (FA) was used to evaluate unidimensionality further. The Kaiser-Meyer-Olkin measure tested sampling adequacy, and Bartlett's Test of Sphericity was used to detect the presence of multiple factors.

An important assumption of the RM is that there is no local response dependency. Local response dependency can occur when items are related to each other in a way that is outside the latent trait the outcome scale is measuring [35]. Local response dependency was evaluated through the calculation of Yens Q3 statistics. It is commonly recommended that these values do not exceed $r=0.7$ [33]. Christensen et al. (2017) proposed that a single critical threshold for Q3 statistics was not appropriate for all situations and that a Q3 value of 0.2 above the average correlation was appropriate [35]. Local response dependency was assessed using both thresholds.

\section{Differential item functioning (DIF)}

DIF tested whether subgroups responded differently to items of the instrument compared with the rest of the sample. There is evidence of DIF when an item's difficulty estimate location on the latent trait varies between subgroups by more than the modelled error [32]. There are two types of DIF. Uniform DIF provides information about whether the outcome scale performs similarly in subgroups while the item difficulties and person measures are held constant. Non-uniform DIF tests the performance of the outcome scale across subgroups at different levels of ability. To evaluate DIF Winsteps uses the Mantel ChiSquared test with (log-)odds estimates of DIF size and tests significance from a comparison of the two groups.
DIF that exceeds 0.64 logits is considered to be moderate to large [33]. The following demographic variables were used for DIF testing: gender, highest educational level (secondary vs tertiary) and signal joint (hip vs knee).

\section{Non-Rasch tests of reliability and construct validity}

Internal consistency was estimated to measure the level of interrelatedness between the items using Cronbach's Alpha from CTT [36]. The threshold for Cronbach's alpha was set at 0.8 . The construct validity of the PAM13 was explored using hypothesis testing [36]. Previous studies in different populations indicated PAM-13 scores were associated with the presence of depressive symptoms and health-related quality of life [37-39]; hence we expected moderate correlations between DASS and AQoL scores with PAM-13 $(r>0.3)$. We hypothesized that weak correlations (if any) would be observed between PAM-13 and HOOS/KOOS 'Pain' and 'Function in daily living' subscale scores $(r<0.2)$. Pearson's correlations were used for normally distributed variables, Spearman's correlations for those that were non-parametric. The thresholds for correlation size were defined as the following: $\geq 0.50$ was large, $0.30-0.49$ moderate, and 0.10-0.29 small [40].

\section{Results \\ Study population}

Out of the 238 participants consecutively enrolled in the OAMP February 2016 to June 2017 and approached to take part in the study, 21 participants declined to participate. The characteristics of the participants who completed the PAM-13 are summarised in Table 2. The group excluded based on non-completion was not large enough to make statistical comparisons.

\section{Item response frequency analysis}

Of 217 attempted PAM-13 surveys, there were no missing responses, however, the N/A responses were not included in the scoring and were treated as missing data [41]. The distribution of responses to the questions is depicted in Fig. 1. The questions most commonly responded to with N/A were PAM-13 item-4 (I know what each of my prescribed medications do) and item11 (I know how to prevent problems with my health), although N/A responses only comprised $2 \%$ (49/2821) of the total responses to these items. The most frequent response category overall was "agree" which comprised $1458 / 2821(52 \%)$ of the total responses, followed by "totally agree" with 813/2921 (29\%) responses. The "disagree" and "totally disagree" categories were much less frequent comprising 403/2821 (14\%) and 98/2821 (3\%) of all responses, respectively.

The mean response scores (range 1-4) for each item decreased from 3.4 (SD 0.73) for item-1 to 2.6 (SD 0.70) for item-11 (see Table 1). Although the mean response 
Table 2 Characteristics of participants

\begin{tabular}{|c|c|c|}
\hline Characteristics & $\begin{array}{l}\text { Included } \\
n=217\end{array}$ & $\begin{array}{l}\text { Excluded } \\
n=21\end{array}$ \\
\hline Sex female, n (\%) & $148(68)$ & $10(48)$ \\
\hline Age years $(S D)$ & $65.5(10.8)$ & $68.7(10.3)$ \\
\hline Signal joint knee n (\%) & $183(84)$ & $15(71)$ \\
\hline Body mass index kg/m²(SD) & $30.3(6.1)$ & $30.0(5.1)$ \\
\hline \multicolumn{3}{|l|}{ PAM raw score } \\
\hline PAM score mean $(S D)^{a}$ & $60.5(11.0)$ & \\
\hline PAM level 1 n (\%) & $10(4.6)$ & \\
\hline PAM level 2 n (\%) & $47(21.7)$ & \\
\hline PAM level 3 n (\%) & $123(56.7)$ & \\
\hline PAM level 4 n (\%) & $28(12.9)$ & \\
\hline \multicolumn{3}{|l|}{ Highest level of education } \\
\hline Year 10 or equivalent n (\%) & $57(26)$ & $4(19)$ \\
\hline Year 12 or equivalent $n(\%)$ & $28(13)$ & $1(5)$ \\
\hline Graduate degree n (\%) & $104(48)$ & $11(52)$ \\
\hline Post graduate degree n (\%) & $22(10)$ & $1(5)$ \\
\hline Missing n (\%) & $6(3)$ & $4(19)$ \\
\hline \multicolumn{3}{|l|}{ Work status } \\
\hline Home duties n (\%) & $6(3)$ & 0 \\
\hline Full time n (\%) & $56(26)$ & $3(14)$ \\
\hline Part-Time n (\%) & $21(10)$ & $3(14)$ \\
\hline Retired n (\%) & $100(46)$ & $8(38)$ \\
\hline Volunteer n (\%) & $4(2)$ & $1(5)$ \\
\hline Other n (\%) & $25(12)$ & $2(10)$ \\
\hline Missing n (\%) & $5(1)$ & $4(19)$ \\
\hline Private hospital n (\%) & $160(74)$ & $21(100)$ \\
\hline Public hospital n (\%) & $57(26)$ & 0 \\
\hline Average pain in last week on VAS ${ }^{b}$ & $n=214$ & $\mathrm{n}=17$ \\
\hline VAS mean (SD) & $4.0(2.3)$ & $3.4(2.5)$ \\
\hline $\operatorname{KOOS}^{\complement}$ & $n=179$ & $n=12$ \\
\hline Pain mean (SD) & $52.3(17.7)$ & $53.6(14.1)$ \\
\hline Function in daily living mean (SD) & $58.0(19.8)$ & $59.3(19.1)$ \\
\hline HOOS $^{d}$ & $n=32$ & $n=3$ \\
\hline Pain mean (SD) & $57.7(19.2)$ & $61.7(16.7)$ \\
\hline Function in daily living mean (SD) & $59.5(18.1)$ & $48.3(20.2)$ \\
\hline DASS-21 & $n=214$ & $n=16$ \\
\hline Depression mean (SD) & $7.2(8.6)$ & $5.2(6.8)$ \\
\hline Anxiety mean (SD) & $5.1(7.3)$ & $3.8(4.3)$ \\
\hline Stress mean (SD) & $8.8(8.5)$ & $7.5(5.2)$ \\
\hline AQoL ${ }^{f}$ & $n=198$ & $n=6$ \\
\hline Independent living mean (SD) & $68.4(19.3)$ & $68.5(15.5)$ \\
\hline Social relationships mean (SD) & $75.4(19.8)$ & $86.7(10.3)$ \\
\hline Mental health mean (SD) & $69.8(21.9)$ & $74.0(11.6)$ \\
\hline Coping mean (SD) & $65.3(20.3)$ & $69.3(8.8)$ \\
\hline
\end{tabular}

Table 2 Characteristics of participants (Continued)

\begin{tabular}{lll}
\hline Characteristics & $\begin{array}{l}\text { Included } \\
n=217\end{array}$ & $\begin{array}{l}\text { Excluded } \\
n=21\end{array}$ \\
\hline Pain mean (SD) & $45.8(22.3)$ & $55.0(18.7)$ \\
Physical senses mean (SD) & $81.8(10.9)$ & $79.7(6.5)$ \\
AQoL summed index mean (SD) & $68.4(14.9)$ & $72.1(8.6)$ \\
\hline
\end{tabular}

PAM: Patient Activation Measure- $0=$ worst, $100=$ best, however, participants with scores of 0 or 100 were excluded from having a final score. PAM level $1=$ least activated, $4=$ most activated

${ }^{\mathrm{b}}$ VAS: Visual analogue scale- average pain over the last week $0=$ no pain, $10=$ worst pain imaginable

c KOOS: Knee injury and Osteoarthritis Outcome Score- $0=$ worst, $100=$ best

${ }^{d}$ HOOS: Hip disability and Osteoarthritis Outcome Score- $0=$ worst, $100=$ best

e DASS: Depression Anxiety Stress Scales- $0=$ best, $42=$ worst

${ }^{\mathrm{f}}$ Assessment of Quality of Life Instrument- Standardised scores-

$0=$ worst, $100=$ best

demonstrated an overall trend of decreasing as the questions became more difficult with subsequent items, the individual item order did not follow the originally established order of the questions [10]: for example, the mean for item-11 (mean 2.6, SD 0.70) was smaller than the means for item-12 and item-13 (mean 2.8, SD 0.70). Floor and ceiling effects were not detected; $1 \%(2 / 217)$ and $3 \%(7 / 217)$ of participants answered with 'totally disagree" and "total agree" to all items respectively.

\section{Reliability and separation}

The person and item reliability of the PAM-13 was adequate as indicated by; person reliability index 0.87 (> reference value 0.8), item reliability index 0.98 (> reference value 0.8 ). The person separation index was 2.58 (> reference value 2) indicating good separation.

\section{Rasch model fit analysis}

There were high positive point measure correlations of $r=0.58-0.78$ for all PAM-13 items. The relationship between the mean difficulty of the items and the ability of participants expressed in logits is depicted in Fig. 2. Overall, the mean difficulty of the PAM-13 questions was lower than the mean ability of this sample. The mean PAM-13 item difficulty was shown at 0 logits, and the mean response of participants was almost 2 logits higher, 37\% (81/217) people had abilities that exceeded the two most difficult items. Figure 2 also shows that the items were not evenly spread with several items having very similar item difficulty (see items 3,6 and 7; items 9, 10 and 12). Moreover, the item difficulty did not ascend uniformly with each subsequent item. This is confirmed by mean item difficulty calibrations (Table 3 ) which showed item difficulty order was different to the original PAM-13. The item difficulty of item-4 (I know what each of my prescribed medications do) was lower than item-3 (I am confident I can help prevent or reduce problems associated with my health. Item-5 (I am confident that I can tell whether I need to go to the 


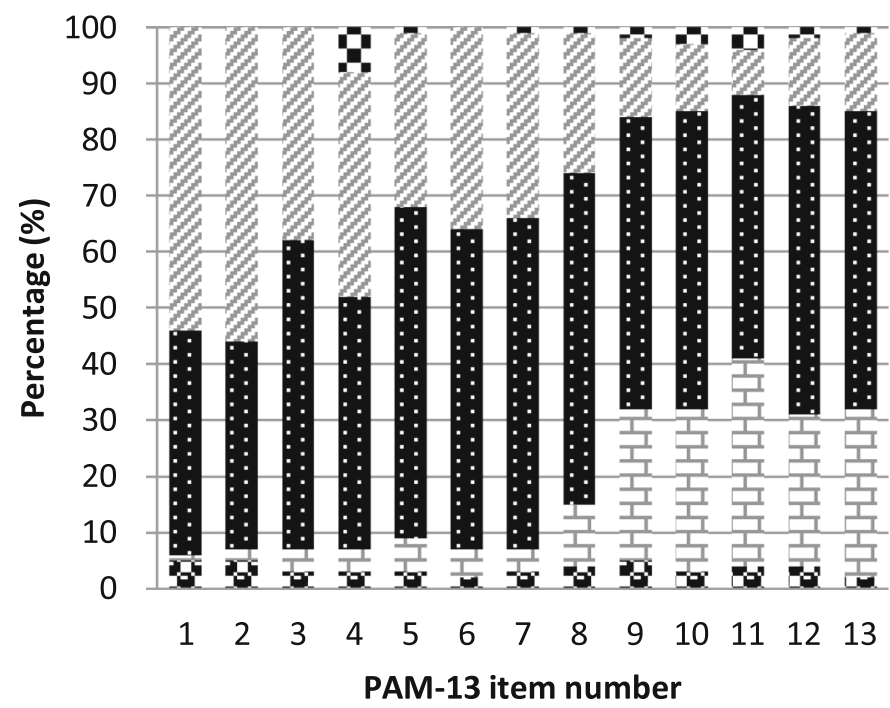

- Not Applicable

Totally Agree

- Agree

- Disagree

Totally Disagree

Fig. 1 Responses across the PAM-13 agreement and not applicable categories $(n=217)$

doctor or whether I can take care of a health problem myself) had higher item difficulty than items-6 and -7 (6. I am confident that I can tell a doctor concerns I have even when he or she does not ask; 7. I am confident that I can follow through on medical treatments I may need to do at home). The greatest deviation between expected and actual order of difficulty was found for item-13 (I am confident that I can maintain lifestyle changes, like eating right and exercising, even during times of stress) which was lower than items 9-12.

Fit statistics are summarised in Table 3. Items fit the RM apart from item-2 with infit and outfit statistics of 1.58 and $1.97 \mathrm{Msq}$ respectively, indicating under-fit. However, the global fit statistic indicated overall adequate fit of the data to the model (log-likelihood $X^{2}=$ $3901.0644,3927+-5$ degrees of freedom, $P=0.612$ ).

\section{Unidimensionality and structural validity}

The Rasch dimension demonstrated that the persons and items within the analysis explained $49.4 \%$ of the variance (49.8\% was expected if the sample fit model perfectly), with an eigenvalue of 12.70. The first contrast gave an eigenvalue of 2.5. Unidimensionality was further assessed using FA. The data was adequate for the FA (Kaiser-Meyer-Olkin value $=0.88$ and Bartlett's Test of Sphericity $\chi^{2}=1404.0, \mathrm{df}$ $78, p<0.001)$. Using a scree plot and principal axis factoring, the PAM-13 loaded on one factor which explained $45.0 \%$ of the variance and suggested unidimensionality. In the assessment of local response dependence, the Yens Q3 values did not exceed the first common threshold of $r=0.7$ suggesting the absence of local response-dependence. According to the second threshold, five items exceeded the Q3 value of 0.2 above the average correlation indicating the presence of local response dependence.

\section{Differential item functioning}

No significant uniform DIF was found for people with hip OA compared with those with knee OA. There was significant uniform DIF for item-13 (I am confident that I can maintain lifestyle changes, like eating right and exercising, even during times of stress) which was more easily endorsed by women; (DIF contrast $=0.98$ logits, Mantel chisquared statistic $\left.\chi^{2}{ }_{M}=11.83, p=0.001\right)$ compared to men. Item-7 (I am confident that I can follow through on medical treatments I may need to do at home) was easier to endorse for people who reported their highest educational level was tertiary vs those whose highest level was high school (DIF contrast $=0.85$ logits, $\chi_{M}^{2}=4.67, p=0.031$ ). Conversely, people whose highest level of education was high school found item-11 (I know how to prevent problems with my health) easier to endorse than those with tertiary level education (DIF contrast $=0.68$ logits, $\chi_{M}^{2}=6.25$, $p=0.012$ ). The subgroups tested in this sample were not large enough to test for non-uniform DIF.

\section{Instrument performance improvement}

The person ability and item responses were assessed on person-item maps that depicted the logit values for all possible response options. The person-item map in Fig. 2 summarises the mean logit response across all response options. There were overlapping of items and similar item difficulties for item-3 (I am confident I can help prevent or reduce problems associated with my health), item-6 (I am confident that I can tell a doctor concerns I have even when he or she does not ask) and item-7 (I am confident that I can follow through on medical treatments I may need to do at home) seen in Fig. 2 and Table 3. It was decided that these items measured distinct aspects of the construct and they were deemed inappropriate for 


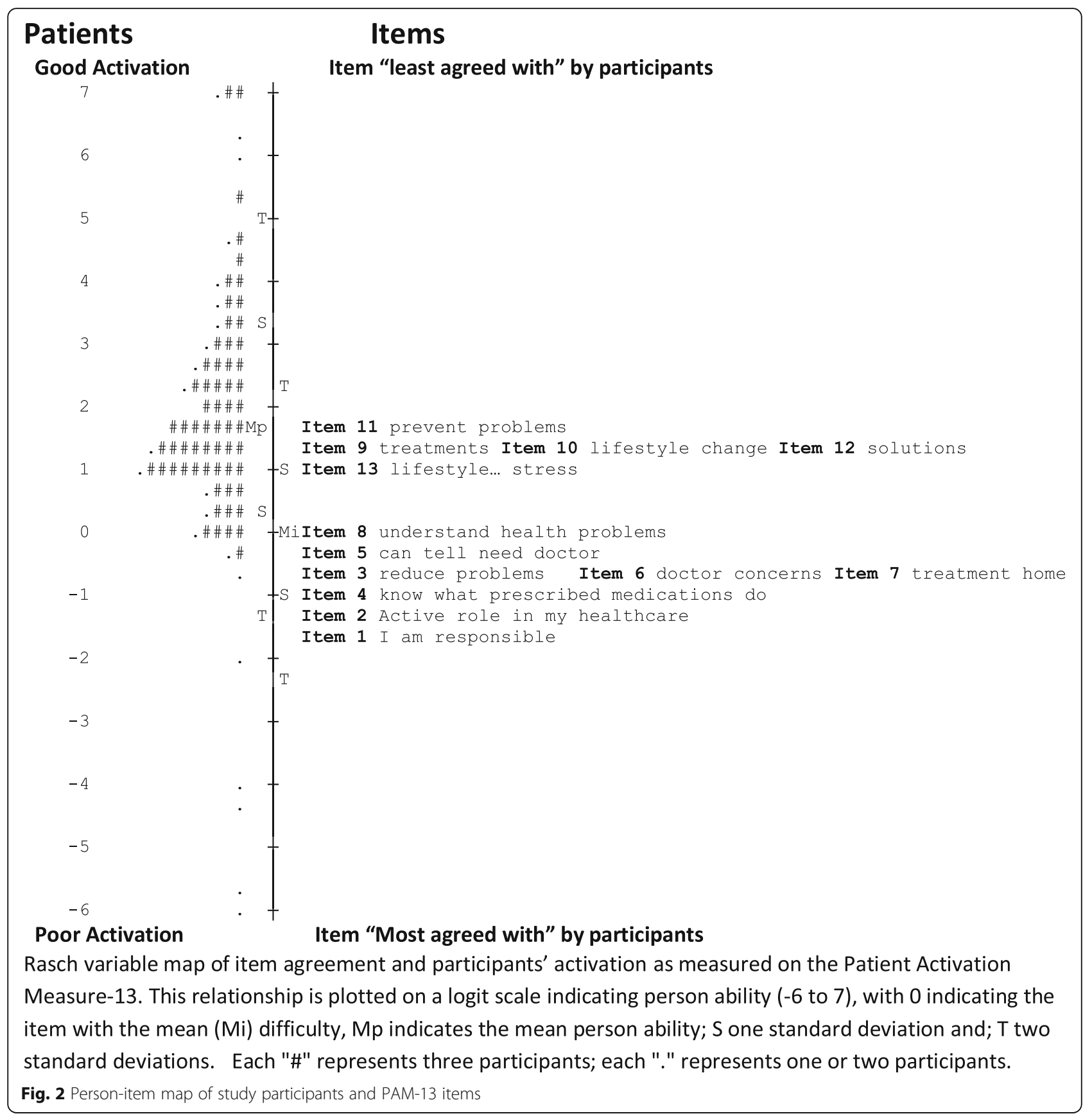

removal. Similarly, items 9, 10 and 12 were overlapping (Fig. 2), however, measured different aspects of the construct and were retained. Item-2 demonstrated poor fit statistics and was similar in item difficulty and content to item-1 (Table 3) so was removed. Removal of item-2 resulted in a slight improvement in the spread of the PAM-13 items (Fig. 3). Reliability remained adequate (person and item reliability 0.87 and 0.98 , respectively) and there were high positive point measure correlations $(r=$ 0.61 to $r=0.79$ ). The fit statistics for the revised model (Table 4) revealed item-1 outfit statistic $1.56 \mathrm{MnSq}$, while the remaining items were acceptable. The PCA showed $49.9 \%$ of the variance was explained by the model (compared with $50.0 \%$ expected) with an eigenvalue of 12.0 . The first contrast resulted in an eigenvalue of 2.2. The analysis following removal of item- 2 did not improve the performance of the instrument adequately to recommend removal of this item in this population.

Non-Rasch tests of reliability and construct validity The estimated Cronbach's Alpha indicated adequate internal consistency $\alpha=0.92$ (> reference value 0.8 ). The 
Table 3 Item fit statistics for the PAM-13

\begin{tabular}{llll}
\hline $\begin{array}{l}\text { PAM items } \\
\text { (in order of difficulty) }\end{array}$ & $\begin{array}{l}\text { Difficulty } \\
\text { calibration } \\
\text { (logits) }\end{array}$ & $\begin{array}{l}\text { Infit } \\
\text { Mean } \\
\text { squared }\end{array}$ & $\begin{array}{l}\text { Outfit } \\
\text { Mean } \\
\text { squared }\end{array}$ \\
\hline 1 & -1.52 & 1.21 & 1.13 \\
2 & -1.50 & $\mathbf{1 . 5 8}$ & $\mathbf{1 . 9 7}$ \\
4 & -1.07 & 1.27 & 1.16 \\
6 & -0.75 & 0.80 & 0.75 \\
3 & -0.75 & 0.95 & 0.89 \\
7 & -0.55 & 0.95 & 1.04 \\
5 & -0.40 & 0.85 & 0.80 \\
8 & 0.11 & 0.74 & 0.70 \\
13 & 1.14 & 1.12 & 1.44 \\
9 & 1.17 & 0.91 & 0.95 \\
10 & 1.19 & 0.96 & 0.97 \\
12 & 1.23 & 0.96 & 0.96 \\
11 & 1.68 & 0.93 & 1.29 \\
\hline
\end{tabular}

Note: Results in bold indicate values that are beyond the ideal cutoffs for infit and outfit statistics (i.e. Msq of $0.5-1.5$ )

correlations between the PAM-13 scores and other variables are summarised in Table 5. Lower activation scores were moderately correlated with the presence of depressive symptoms on the DASS; $r=-0.26$, (95\% Confidence interval (CI) $-0.38,-0.14)$. Higher activation scores correlated moderately with higher health-related quality of life score as measured on the AQoL; $r=0.32$ (95\% CI $0.18,0.47)$. There were small correlations between PAM-13 and KOOS pain and ADL scores $(r=0.13(95 \%$ CI $0.03,0.29)$ and $r=0.15$ (95\% CI $0.03,0.31)$ respectively). There were no significant correlations between PAM-13 and HOOS pain or function scores.

\section{Discussion}

\section{Discussion}

Adequate person and item reliability was demonstrated for the PAM-13 and unidimensionality was evaluated. There were some issues with targeting items to people with higher abilities and the item-order was different from that expected for the PAM-13. Rasch analysis revealed that item- 2 under-fit the model and its removal resulted in a very slightly improved model fit, but not enough to recommend its removal. There was evidence of a difference in item response based on sex and educational status, though this was limited to a small number of items. The presence of depressive symptoms and AQoL scores correlated moderately with PAM-13 as expected.

International studies commonly report a different item difficulty order to the original order for PAM-13 published in American cohorts [10, 12, 15, 42-44]. This was consistent with the findings of our study with the exception of three items: -1 (When all is said and done, I am the person who is responsible for taking care of my health); -2 (Taking an active role in my own health care is the most important thing that affects my health) and 12 (I am confident I can figure out solutions when new problems arise with my health) [10]. These were also the only items consistent with the original order in a Canadian study of participants with neurological conditions [12]. Items- 1 and -2 alone followed the original order of item difficulty in a study of adults in Korea living with OA [15]. Item-1 was the 'easiest' item in a Danish study [43], but not in studies of the German and Italian PAM-13 in people with chronic conditions [42, 44]. Differences in item-difficulty order seen in our study and other populations may be attributed to specific disease and cultural factors. The differences in self-management tasks required and corresponding difficulty of these should be considered in the context of the health conditions and populations in which the PAM-13 is used.

The unidimensionality of the PAM-13 was assessed; almost $50 \%$ of the variance was explained by the items and participant responses. This percentage of explained variation was higher than reported in other disease populations [42-44], but not as high as that reported for the Korean version of PAM-13 tested in an OA sample (57.5\%) [15]. The limited proportion of variance explained suggests there may be other additional factors that comprise this construct that are not captured by the items of the instrument. On the other hand, it may indicate simply that the items were of similar difficulty and the participants in the study were of similar ability [33]. This study relied on the PCA of Rasch residuals and conventional factor analysis. Further information on the unidimensionality of PAM-13 in this population using other statistical tests such as confirmatory factor analysis based on polychoric correlations or further Rasch based tests may be valuable in future research.

The assessment of local response dependence using two different thresholds of Q3 values yielded conflicting results. The conventional threshold Q3 value indicated the absence of local response dependence. The second threshold of the mean Q3 +0.2 suggested the presence of local response dependence. To confirm these results, it would be helpful to attempt to replicate these results in future studies. This could also provide further evidence regarding the potential for different results produced by commonly recommended thresholds versus thresholds that are influenced by the characteristics of the dataset being analysed.

There were issues identified with targeting of the PAM-13 items. Looking at the person-item map from this study (Fig. 2), the ability of the participants most often exceeded the difficulty of the items. The lack of items of sufficient difficulty could affect the precision of 


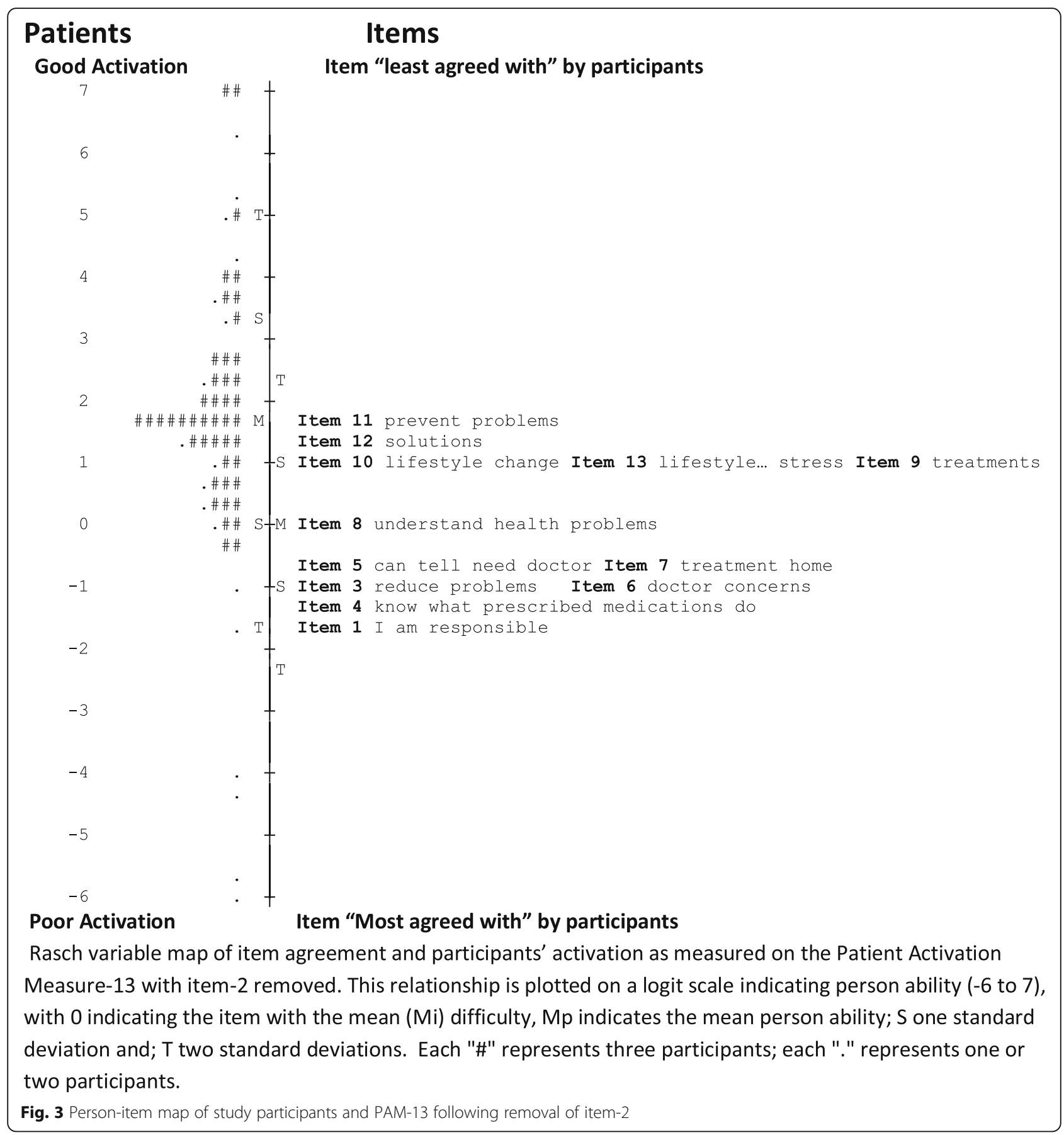

the measure for people with greater ability (i.e. greater probability of agreeing or partially agreeing with the items). A possible way of dealing with both the low proportion of explained variance and limited targeting of items to people with higher abilities may be to develop an OA-specific version of the PAM-13 in a similar way the version was developed for mental health (PAM-MH) [45]. An important implication of modifying the PAM-13 to be condition-specific would be the loss of the ability to compare populations and the relative impact of different medical conditions and/or treatments. Further, people with OA commonly report the presence of several chronic comorbidities [46]; it is arguably more useful to use a generic instrument and consider self-management of health in general.

There were a few incidences of significant uniform DIF in this study., Significant DIF was found for item-13 (I am confident that I can maintain lifestyle changes, like eating right and exercising, even during times of stress) suggesting that women find it more difficult to endorse 
Table 4 Item fit statistics for the PAM-13 following removal of items -2

\begin{tabular}{llll}
\hline $\begin{array}{l}\text { PAM items } \\
\text { (in order of difficulty) }\end{array}$ & $\begin{array}{l}\text { Difficulty } \\
\text { calibration }\end{array}$ & $\begin{array}{l}\text { Infit } \\
\text { Mean } \\
\text { squared }\end{array}$ & $\begin{array}{l}\text { Outfit } \\
\text { Mean } \\
\text { squared }\end{array}$ \\
\hline 1 & -1.73 & 1.40 & $\mathbf{1 . 5 6}$ \\
4 & -1.25 & 1.32 & 1.19 \\
6 & -0.92 & 0.83 & 0.78 \\
3 & -0.92 & 1.04 & 0.99 \\
7 & -0.72 & 1.00 & 1.11 \\
5 & -0.55 & 0.88 & 0.84 \\
8 & -0.02 & 0.75 & 0.7 \\
13 & 1.07 & 1.14 & 1.42 \\
9 & 1.10 & 0.90 & 0.93 \\
10 & 1.13 & 0.95 & 0.95 \\
12 & 1.17 & 0.97 & 0.97 \\
11 & 1.65 & 0.92 & 1.23 \\
\hline
\end{tabular}

Note: Results in bold indicate values that are beyond the ideal cutoffs for infit and outfit statistics (ie. Msq of $0.5-1.5$ )

this item. A systematic review synthesised determinants of adherence to lifestyle intervention in adults with obesity [47] and found that being female was a predictor of attrition from lifestyle interventions. Given that the mean BMI for our study sample was $30.3 \mathrm{~m} / \mathrm{kg}^{2}$, most of the participants were overweight/obese, so this could offer some evidence relating to why women found it more difficult to endorse this item. This finding is consistent with one study of PAM-13 in a different population (Italian speaking people with chronic diseases) [42], however, there was no significant DIF identified for gender in the OA Korean PAM-13 study [15].

Our analysis found that PAM Item-7 (I am confident that I can follow through on medical treatments I may need to do at home) was easier to endorse for those people with higher formal educational level. This result conflicted with the findings of an Italian study reporting that people with higher education levels found this item more difficult to endorse [42]. There is existing evidence that suggests people with higher education levels feel more confident in self-management of their OA. A large cohort study found that people with OA, who had higher educational levels, reported higher Arthritis Self Efficacy Scale (ASES) scores. The ASES measures the ability of people to manage the symptoms of their OA [48]. Interestingly, another finding in our study was that item-11 (I know how to prevent problems with my health) was harder to endorse for participants with higher education levels. This is an unexpected finding, we would expect people with higher educational levels to be confident of not only how to manage their OA at home, but also of how to prevent problems. This result was not reported in other studies of the PAM-13. The DIF identified for three PAM-13 items in this study indicates potential bias in the measurement of patient activation in subgroups of people living with hip and knee OA. This should be investigated in future studies and if DIF is found for the same items, there are several ways that this could be managed, such as removal of those items [49].

This is the first time, to our knowledge that a study, has examined measurement properties of the English language version PAM in a sample of people living with OA. There is growing interest in the utility of the PAM13, particularly in the United Kingdom where the PAM13 is being appraised as a tool used to evaluate care for chronic conditions in the National Health Service [50]. It is important to improve our understanding of the measurement properties of PAM-13 in different disease populations and this study is a valuable contribution to this growing body of evidence.

There are some limitations to the applicability of this study which included a fairly homogenous population from a higher socio-demographic region of Australia. Future studies should aim to include a less geographically and socio-demographically homogenous sample. There was also a large proportion of people in our study with knee OA so that the sample was less representative of people with hip OA. Future studies should assess larger groups of participants with hip OA to ensure that accurate measurement properties are available for people with this disease.

Table 5 Correlations between Patient Activation Measure-13 scores and other variables

\begin{tabular}{llll}
\hline & Expected correlation $^{\text {a }}$ & Actual correlation & 95\% Confidence interval \\
\hline DASS depression $^{5}(n=205)$ & $<-0.3$ & -0.26 & $-0.38,-0.14$ \\
AQoL $(n=190)$ & $>0.5$ & 0.32 & $0.18,0.47$ \\
KOOS Pain $(n=171)$ & $<0.2$ & 0.13 & $0.03,0.29$ \\
KOOS ADL $(n=171)$ & $<0.2$ & 0.15 & $0.03,0.31$ \\
HOOS Pain & $(n=31)$ & -0.06 & $-0.47,0.39$ \\
HOOS ADL $^{a}(n=31)$ & $<0.2$ & -0.23 & $-0.54,0.15$ \\
\hline
\end{tabular}

Pearson's correlations were used for normally distributed variables, ${ }^{\text {a} S p e a r m a n ' s ~ c o r r e l a t i o n s ~ f o r ~ t h o s e ~ t h a t ~ w e r e ~ n o n-p a r a m e t r i c . ~ D A S S: ~ D e p r e s s i o n ~ A n x i e t y ~ S t r e s s ~}$ Scales- $0=$ best, 42 = worst. AQoL: Assessment of Quality of Life Instrument- Standardised scores- $0=$ worst, $100=$ best. KOOS: Knee injury and Osteoarthritis Outcome Score- $0=$ worst, $100=$ best. HOOS: Hip disability and Osteoarthritis Outcome Score- $0=$ worst, $100=$ best. 


\section{Conclusions}

There is limited extant measurement property evidence available to support the use of any instrument assessing OA self-management attitudes and capabilities. This study provides evidence of adequate person and item reliability, unidimensionality, and construct validity to support the use of PAM-13 to measure patient activation in people living with OA. Potential areas for concern regarding the PAM13 responses from this sample include possible local response dependence, DIF and issues with targeting. Further studies of the measurement properties of the PAM-13 in people with OA are recommended for the purposes of research, and to provide information about how the PAM-13 can be used with individual OA patients in the clinic.

\section{Abbreviations \\ PAM-13: Patient Activation Measure 13 item version; OA: Osteoarthritis; DIF: Differential item functioning; OAMP: Osteoarthritis management program; HREC: Human Research Ethics Committee; N/A: Not applicable; HOOS: The hip disability and osteoarthritis outcome score; KOOS: Knee injury and Osteoarthritis Outcome Score; DASS-21: Depression, Anxiety and Stress Scale 21 item version; AQoL-6D: Assessment of Quality of Life 6 dimension version; BMI: Body mass index; RM: Rasch model; CTT: Classical test theory; MnSq: Mean square; PCA: Principal components analysis; FA: Factor analysis; SD: Standard deviation; $x^{2}$ : Chi squared; df: Degrees of freedom; $X^{2}{ }_{\text {мн: }}$ : Mantel-Haenszel chi-squared statistic; PAM-MH: Patient Activation Measure Mental Health version}

\section{Acknowledgements}

We would like to acknowledge the participants of the OA chronic disease management programs at Hunters Hill, Royal North Shore and Mount Wilga Hospitals who graciously completed the PAM-13 and the other patientreported outcomes used as part of the program.

\section{Authors' contributions}

We confirm that all authors were involved in: the conception and design of the study, or acquisition of data, or analysis and interpretation of data, drafting the article or revising it critically for important intellectual content, final approval of the version to be submitted.

\section{Authors' information}

N/A.

\section{Funding}

this manuscript represents the work of a PhD project that did not receive any specific grant from funding agencies in the public, commercial, or notfor-profit sectors.

\section{Availability of data and materials}

The datasets used and/or analysed during the current study are available from the corresponding author on reasonable request.

\section{Ethics approval and consent to participate}

Ethical approval for this study in accordance with the Declaration of Helsinki was provided by Human Research Ethics Committees (HREC): Hunters Hill Hospital NSPHEC 2016-LNR-007; Mount Wilga Hospital NSPHEC 2017-LNR-005 and Northern Sydney Local Health District reference: RESP/16/11, HREC reference: LNRI16/HAWKE/14. Participants provided consent to participate in this study and were able to opt out of having their data included in analyses.

\section{Consent for publication}

n/a We confirm all patient/personal identifiers have been removed or disguised so the patient/person(s) described are not identifiable and cannot be identified through the details of the story.

\section{Competing interests}

The authors declare that they have no competing interests.

\section{Author details}

Tolling Institute of Medical Research, Institute of Bone and Joint Research, Faculty of Medicine and Health, University of Sydney, Sydney, Australia. ${ }^{2}$ Department of Rheumatology, Royal North Shore Hospital , Sydney, Australia. ${ }^{3}$ Physiotherapy Department, Royal North Shore Hospital, Sydney, Australia. ${ }^{4}$ Faculty of Medicine and Health Sciences, Macquarie University, Sydney, Australia. ${ }^{5}$ Rehabilitation Department, Hunters Hill Private Hospital, Sydney, Australia. ${ }^{6}$ Physiotherapy Department, Mount Wilga Private Hospital, Sydney, Australia.

Received: 6 July 2018 Accepted: 14 April 2020

Published online: 05 May 2020

\section{References}

1. Vos T, Flaxman AD, Naghavi M, Lozano R, Michaud C, Ezzati M, et al. Years lived with disability (YLDs) for 1160 sequelae of 289 diseases and injuries 1990-2010: a systematic analysis for the global burden of disease study 2010. Lancet. 2012;380(9859):2163-96.

2. Xie F, Kovic B, Jin X, He X, Wang M, Silvestre C. Economic and humanistic burden of osteoarthritis: a systematic review of large sample studies. Pharmacoeconomics. 2016;34(11):1087-100.

3. Meneses SR, Goode AP, Nelson AE, Lin J, Jordan JM, Allen KD, et al. Clinical algorithms to aid osteoarthritis guideline dissemination. Osteoarthr Cartil. 2016;24(9):1487-99.

4. Du S, Yuan C, Xiao X, Chu J, Qiu Y, Qian H. Self-management programs for chronic musculoskeletal pain conditions: a systematic review and metaanalysis. Patient Educ Couns. 2011;85(3):e299-310.

5. Kroon FP, van der Burg LR, Buchbinder R, Osborne RH, Johnston RV, Pitt V. Self-management education programmes for osteoarthritis. Cochrane Database Syst Rev. 2014;1(1):CD008963.

6. McAllister M, Dunn G, Payne K, Davies L, Todd C. Patient empowerment: the need to consider it as a measurable patient-reported outcome for chronic conditions. BMC Health Serv Res. 2012;12:157.

7. de Vet H, Terwee C, Mokkink L, Knol D. Measurement in medicine: a practical guide to biostatistics and epidemiology. London: Cambridge University Press; 2011.

8. Tugwell $P$, Boers M, D'Agostino MA, Beaton D, Boonen A, Bingham CO 3rd, et al. Updating the OMERACT filter: implications of filter 2.0 to select outcome instruments through assessment of "truth": content, face, and construct validity. J Rheumatol. 2014:41(5):1000-4.

9. Eyles JP, Hunter DJ, Meneses SRF, Collins NJ, Dobson F, Lucas BR, et al. Instruments assessing attitudes toward or capability regarding selfmanagement of osteoarthritis: a systematic review of measurement properties. Osteoarthr Cartil. 2017;25(8):1210-22.

10. Hibbard JH, Mahoney ER, Stockard J, Tusler M. Development and testing of a short form of the patient activation measure. Health Serv Res. 2005;40(6 Pt 1):1918-30.

11. Moljord IE, Lara-Cabrera ML, Perestelo-Perez L, Rivero-Santana A, Eriksen L, Linaker OM. Psychometric properties of the Patient Activation Measure-13 among out-patients waiting for mental health treatment: a validation study in Norway. Patient Educ Couns. 2015;98(11):1410-7.

12. Packer TL, Kephart G, Ghahari S, Audulv A, Versnel J, Warner G. The patient activation measure: a validation study in a neurological population. Qual Life Res. 2015;24(7):1587-96.

13. Schmaderer M, Pozehl B, Hertzog M, Zimmerman L. Psychometric properties of the patient activation measure in multimorbid hospitalized patients. J Nurs Meas. 2015;23(3):128-41.

14. Skolasky RL, Green AF, Scharfstein D, Boult C, Reider L, Wegener ST. Psychometric properties of the patient activation measure among multimorbid older adults. Health Serv Res. 2011;46(2):457-78.

15. Ahn $\mathrm{YH}, \mathrm{Yi} \mathrm{CH}, \mathrm{Ham} \mathrm{OK}$, Kim BJ. Psychometric properties of the Korean version of the "patient activation measure 13" (PAM13-K) in patients with osteoarthritis. Eval Health Prof. 2015;38(2):255-64.

16. Santesso N, Rader T, Wells GA, O'Connor AM, Brooks PM, Driedger M, et al. Responsiveness of the effective consumer scale (EC-17). J Rheumatol. 2009; 36(9):2087-91.

17. Hibbard JH, Greene J, Shi Y, Mittler J, Scanlon D. Taking the long view: how well do patient activation scores predict outcomes four years later? Med Care Res Rev. 2015;72(3):324-37. 
18. Hibbard JH, Mahoney ER, Stock R, Tusler M. Do increases in patient activation result in improved self-management behaviors? Health Serv Res. 2007;42(4):1443-63.

19. Sacks RM, Greene J, Hibbard J, Overton V, Parrotta CD. Does patient activation predict the course of type 2 diabetes? A longitudinal study. Patient Educ Couns. 2017;100(7):1268-75.

20. Rasch G. Probabilistic model for some intelligence and achievement tests. Denmark: Danish Institute for Educational Research; 1960.

21. Tennant A, Conaghan PG. The Rasch measurement model in rheumatology: what is it and why use it? When should it be applied, and what should one look for in a Rasch paper? Arthritis Care Res. 2007;57(8):1358-62.

22. Eyles JP, Lucas BR, Patterson JA, Williams MJ, Weeks K, Fransen M, et al. Does clinical presentation predict response to a nonsurgical chronic disease management program for Endstage hip and knee osteoarthritis? J Rheumatol. 2014:41(11):2223-31.

23. Musuloskeletal Network, Agency for Clinical Innovation. Osteoarthritis Chronic Care Program Pilot Site manual version 2. New South Wales: Agency for Clinical Innovation; 2017. https://www.aci.health.nsw.gov.au/_ data/assets/pdf_file/0006/390057/ACI_OACCP-Site-Manual-Oct-2017.pdf.

24. Hawker GA, Mian S, Kendzerska T, French M. Measures of adult pain: visual analog scale for pain (VAS pain), numeric rating scale for pain (NRS pain), McGill pain questionnaire (MPQ), short-form McGill pain questionnaire (SFMPQ), chronic pain grade scale (CPGS), short Form-36 bodily pain scale (SF36 BPS), and measure of intermittent and constant osteoarthritis pain (ICOAP). Arthritis Care Res (Hoboken). 2011;63(Suppl 11):S240-52.

25. Linden A. Estimating Measurement Error of the Patient Activation Measure for Respondents with Partially Missing Data. Biomed Res Int. 2015;2015: 270168

26. Thorborg K, Roos EM, Bartels EM, Petersen J, Holmich P. Validity, reliability and responsiveness of patient-reported outcome questionnaires when assessing hip and groin disability: a systematic review. BJSM. 2010;44(16): 1186-96.

27. Roos EM, Lohmander LS. The knee injury and osteoarthritis outcome score (KOOS): from joint injury to osteoarthritis. Health Qual Life Outcomes. 2003;1:64.

28. Lovibond PF, Lovibond SH. The structure of negative emotional states: comparison of the depression anxiety stress scales (DASS) with the Beck depression and anxiety inventories. Behav Res Ther. 1995;33(3):335-43.

29. Richardson J, Atherton Day N, Peacock S, lezzi A. Measurement of the quality of life for economic evaluation and the assessment of quality of life (AQoL) mark 2 instrument. Aust Econ Rev. 2004;37(1):62-88.

30. Mokkink LB, Terwee CB, Patrick DL, Alonso J, Stratford PW, Knol DL, et al. The COSMIN checklist for assessing the methodological quality of studies on measurement properties of health status measurement instruments: an international Delphi study. Qual Life Res. 2010;19(4):539-49.

31. Terwee CB, Bot SD, de Boer MR, van der Windt DA, Knol DL, Dekker J, et al. Quality criteria were proposed for measurement properties of health status questionnaires. J Clin Epidemiol. 2007;60(1):34-42.

32. Bond TG. In: Bond TG, Fox CM, Fox CM, Ebscohost, editors. Applying the Rasch model : fundamental measurement in the human sciences. New York: Routledge, Taylor \& Francis Group; 2015.

33. Linacre JM. Winsteps ${ }^{\oplus}$ Rasch measurement computer program User's guide. Beaverton: Winsteps.com; 2017.

34. Linacre J. Sample size and item calibration stability. Rasch Measurement Transact. 1994;7(4):328.

35. Christensen KB, Makransky G, Horton M. Critical values for Yen's Q3: identification of local dependence in the Rasch model using residual correlations. Appl Psychol Measur. 2017;41(3):178-94.

36. Mokkink LB, Terwee CB, Patrick DL, Alonso J, Stratford PW, Knol DL, et al The COSMIN study reached international consensus on taxonomy, terminology, and definitions of measurement properties for health-related patient-reported outcomes. J Clin Epidemiol. 2010;63(7):737-45.

37. Blakemore A, Hann M, Howells K, Panagioti M, Sidaway M, Reeves D, et al. Patient activation in older people with long-term conditions and multimorbidity: correlates and change in a cohort study in the United Kingdom. BMC Health Serv Res. 2016;16(1):582

38. Magnezi R, Glasser S, Shalev H, Sheiber A, Reuveni H. Patient activation, depression and quality of life. Patient Educ Couns. 2014;94(3):432-7.

39. Stepleman L, Rutter MC, Hibbard J, Johns L, Wright D, Hughes M. Validation of the patient activation measure in a multiple sclerosis clinic sample and implications for care. Disabil Rehabil. 2010:32(19):1558-67.

40. Field A. Discovering statistics using SPSS. 3rd ed. London: Sage; 2009.
41. Insignia Health. Patient Activation Measure (PAM) $13^{\text {TM }}$. Portland: Insignia Health LLC; 2014

42. Graffigna G, Barello S, Bonanomi A, Lozza E, Hibbard J. Measuring patient activation in Italy: translation, adaptation and validation of the Italian version of the patient activation measure 13 (PAM13-I). BMC Med Inform Decis Mak 2015;15:109.

43. Maindal HT, Sokolowski I, Vedsted P. Translation, adaptation and validation of the American short form patient activation measure (PAM13) in a Danish version. BMC Public Health. 2009:9:209.

44. Zill JM, Dwinger S, Kriston L, Rohenkohl A, Harter M, Dirmaier J. Psychometric evaluation of the German version of the patient activation measure (PAM13). BMC Public Health. 2013;13:1027.

45. Green CA, Perrin NA, Polen MR, Leo MC, Hibbard JH, Tusler M. Development of the patient activation measure for mental health. Adm Policy Ment Health. 2010:37(4):327-33.

46. Harrison C, Henderson J, Miller G, Britt $H$. The prevalence of complex multimorbidity in Australia. Aust N Z J Public Health. 2016;40(3):239-44.

47. Burgess $E$, Hassmen P, Pumpa KL. Determinants of adherence to lifestyle intervention in adults with obesity: a systematic review. Clin Obes. 2017;7(3): 123-35.

48. Lorig $\mathrm{K}$, Chastain RL, Ung E, Shoor S, Holman HR. Development and evaluation of a scale to measure perceived self-efficacy in people with arthritis. Arthritis Rheum. 1989;32(1):37-44.

49. Teresi JA. Different approaches to differential item functioning in health applications. Advantages, disadvantages and some neglected topics. Med Care. 2006:44(11 Suppl 3):S152-70.

50. Roberts NJ, Kidd L, Dougall N, Patel IS, McNarry S, Nixon C. Measuring patient activation: the utility of the patient activation measure within a UK context-results from four exemplar studies and potential future applications. Patient Educ Couns. 2016;99(10):1739-46.

\section{Publisher's Note}

Springer Nature remains neutral with regard to jurisdictional claims in published maps and institutional affiliations.
Ready to submit your research? Choose BMC and benefit from:

- fast, convenient online submission

- thorough peer review by experienced researchers in your field

- rapid publication on acceptance

- support for research data, including large and complex data types

- gold Open Access which fosters wider collaboration and increased citations

- maximum visibility for your research: over $100 \mathrm{M}$ website views per year

At $\mathrm{BMC}$, research is always in progress.

Learn more biomedcentral.com/submissions 